\title{
Catalytic Hydrogen-Chlorine Exchange between Chlorinated Hydrocarbons under Oxygen-Free Conditions**
}

\author{
Alwies W. A. M. van der Heijden, Simon G. Podkolzin, Mark E. Jones, Johannes H. Bitter, and \\ Bert M. Weckhuysen*
}

Chlorinated hydrocarbons (CHCs) remain important industrial chemical intermediates and solvents, especially for the exploration of the potential of La-based materials for the conversion of chlorinated waste compounds. ${ }^{[1]}$ The production of industrially important CHCs frequently occurs with concurrent formation of less desirable side-products. For example, mixtures of chlorinated $\mathrm{C}_{1}$ and $\mathrm{C}_{2}$ hydrocarbons are still formed as by-products in industrial processes such as the production of vinyl chloride monomer (VCM). ${ }^{[2,3]}$ Another example is carbon tetrachloride $\left(\mathrm{CCl}_{4}\right)$ formation in the production of chloroform $\left(\mathrm{CHCl}_{3}\right)$ and other chlorinated methanes. The United States Clean Air Act and the Montreal Protocol limit the production and sale of $\mathrm{CCl}_{4},{ }^{[4,5]}$ therefore methods to effectively recycle chlorinated side-products, in particular $\mathrm{CCl}_{4}$, would be advantageous. The hydrogenchlorine exchange of $\mathrm{CCl}_{4}$ with other $\mathrm{CHCs}$, such as $\mathrm{CH}_{2} \mathrm{Cl}_{2}$, for the recycling of less desirable compounds into valuable products would be of particular interest.

The reaction thermodynamics favor the use of $\mathrm{CCl}_{4}$ as a $\mathrm{Cl}$ source with methane or a chloromethane. The best known way to run these reactions is thermal gas-phase radical chemistry, ${ }^{[6,7]}$ although the main disadvantage of radical chemistry is its low selectivity due to the formation of various chloromethanes and $\mathrm{C}_{n}(n \geq 2)$ coupling products. ${ }^{[6,7]}$ Coke formation at the temperatures required for radical generation also lowers product yields and can foul the equipment. As a result, the commercial application of this reaction does not currently appear to be economically attractive, and incineration is commonly used as a route for disposing of $\mathrm{CCl}_{4}$. To our knowledge, there is only a single report on the catalytic exchange of $\mathrm{H}$ and $\mathrm{Cl}$ atoms between chlorinated hydro-

[*] A. W. A. M. van der Heijden, Dr. J. H. Bitter,

Prof. Dr. ir. B. M. Weckhuysen

Inorganic Chemistry and Catalysis Group

Department of Chemistry

Utrecht University

Sorbonnelaan 16, 3584 CA Utrecht (The Netherlands)

Fax: (31) 30-251-1027

E-mail: b.m.weckhuysen@uu.nl

Dr. S. G. Podkolzin, Dr. M. E. Jones

The Dow Chemical Company

Core Research and Development

Midland, Michigan 48674 (USA)

[**; The authors thank NWO-CW VICI for financial support. The metathesis reaction between $\mathrm{CCl}_{4}$ and $\mathrm{CH}_{2} \mathrm{Cl}_{2}$ was discovered by Mark E. Jones at the Dow Chemical Company. The carbon nanofibers were synthesized by Arjan J. Plomp.

9 Supporting information for this article is available on the WWW under http://www.angewandte.org or from the author. carbons, namely the reaction of $\mathrm{CCl}_{4}$ with methane to produce $\mathrm{CH}_{3} \mathrm{Cl}$ over supported $\mathrm{Pt}$ catalysts. ${ }^{[8]}$ However, as the reported catalysts also degrade due to conversion of their oxide supports into chlorinated compounds, the authors advocate addition of gas-phase oxygen to the feed to remedy the coke formation even though this inevitably leads to the formation of oxidation products and lower selectivity.

Catalytic systems for activating $\mathrm{C}-\mathrm{H}$ and $\mathrm{C}-\mathrm{Cl}$ bonds generally use oxygen-containing compounds in the feed because they provide a thermodynamic driving force, as in oxidation of methane to methanol and acetic acid ${ }^{[9,10]}$ or concurrent water formation in the oxidative coupling of methane. ${ }^{[11]}$ Kinetically limiting oxidation and preventing thermodynamically favorable total combustion is difficult, and even selective bond activation remains a challenge, ${ }^{[12,13]}$ therefore the development of more efficient catalysts for complete oxidative destruction of hydrocarbons and chlorinated hydrocarbons remains an area of active research. Recent examples in this field include combustion over uranium-oxide catalysts, ${ }^{[14]}$ reaction with $\mathrm{H}_{2} \mathrm{O}_{2}$ over an iron catalyst, ${ }^{[15]}$ and our own publications on the destructive adsorption over lanthanum-based catalysts. ${ }^{[16-21]}$

Lanthanum-based catalysts have also recently been reported to selectively activate hydrocarbons such as methane and ethane. ${ }^{[22,23]}$ Previous studies have suggested that the presence of oxygen is critical for activation of both $\mathrm{C}-\mathrm{H}$ and $\mathrm{C}-\mathrm{Cl}$ bonds over these catalytic materials, therefore the destructive adsorption reaction is proposed to proceed via an exchange of two chlorine atoms for one oxygen atom. ${ }^{[16-21]}$ If lattice oxygen is depleted, the reaction stops. In the case of $\mathrm{C}^{-}$ $\mathrm{H}$ bond activation in the oxidative hydrochlorination of methane, the reaction is proposed to proceed via exchange of a hydrogen atom for a chlorine atom. ${ }^{[22]}$ This $\mathrm{H}$-for- $\mathrm{Cl}$ exchange, however, only takes place when the surface $\mathrm{Cl}$ species are activated in the presence of $\mathrm{O}_{2}$, and the reaction stops without $\mathrm{O}_{2}$. Herein we report that $\mathrm{LaCl}_{3}$ is an active and stable catalyst for the hydrogen-chlorine exchange reaction between $\mathrm{CH}_{2} \mathrm{Cl}_{2}$ and $\mathrm{CCl}_{4}$, selectively yielding $\mathrm{CHCl}_{3}$ under oxygen-free conditions.

The gas-phase reaction between $\mathrm{CCl}_{4}$ and $\mathrm{CH}_{2} \mathrm{Cl}_{2}$ under our experimental conditions yields $\mathrm{CHCl}_{3}$ in only trace amounts. To correct for these gas-phase reactions, the results from the catalytic experiments (Figure 1) were adjusted by subtracting the results obtained under the same conditions obtained from blank experiments with either quartz pellets or carbon nanofibers (CNFs). Before testing, all catalysts were chlorinated under the appropriate conditions to ensure complete substitution of all lattice oxygen for chlorine to 


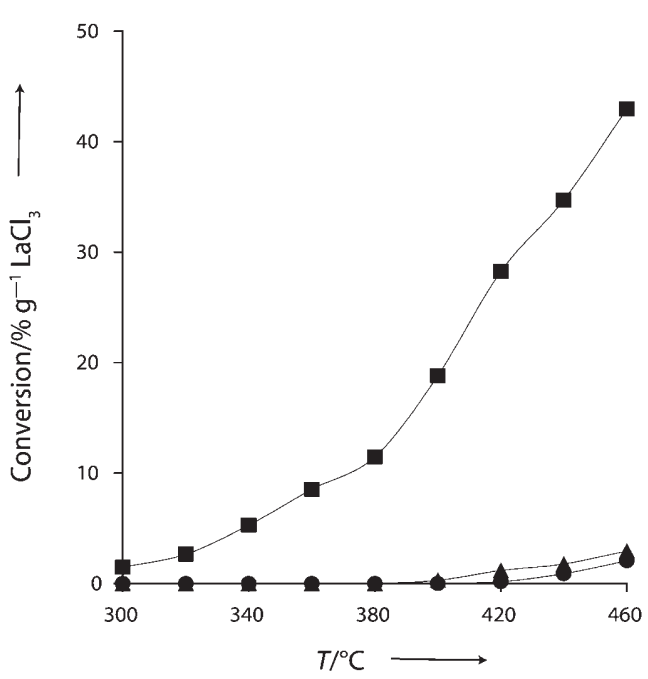

Figure 1. Conversion of a mixture of $\mathrm{CH}_{2} \mathrm{Cl}_{2}$ and $\mathrm{CCl}_{4}$ into $\mathrm{CHCl}_{3}$ as a function of temperature over bulk $\mathrm{LaCl}_{3}$ synthesized by chlorination of $\mathrm{LaCl}_{3} \cdot 7 \mathrm{H}_{2} \mathrm{O}$ with $\mathrm{CCl}_{4}(\bullet)$, bulk $\mathrm{LaCl}_{3}$ synthesized by chlorination of $\mathrm{LaOCl}$ with $\mathrm{HCl}(\mathbf{\Delta})$, and $20 \mathrm{wt} \% \mathrm{LaCl}_{3}$ supported on CNF $(\mathbf{-})$ ( $\mathrm{GHSV}=400 \mathrm{~h}^{-1}$; inlet concentration: $\mathrm{CCl}_{4}=\mathrm{CH}_{2} \mathrm{Cl}_{2}=4.7$ vol\% in $\mathrm{He}$ ).

prevent destructive adsorption of the reactants. The concentration of the chlorinating agent was determined by GC analysis. Once the uptake of chlorinating agent by the catalyst ceased, the material was deemed to be fully chlorinated. For the first set of experiments, a bulk $\mathrm{LaCl}_{3}$ catalyst was synthesized by chlorinating $\mathrm{LaCl}_{3} \cdot 7 \mathrm{H}_{2} \mathrm{O}$ with $\mathrm{CCl}_{4}$. Figure 1 shows that this catalyst has a low, but appreciable, activity for $\mathrm{H}-\mathrm{Cl}$ exchange between $\mathrm{CCl}_{4}$ and $\mathrm{CH}_{2} \mathrm{Cl}_{2}$ (Reaction 1) with

$\mathrm{CH}_{2} \mathrm{Cl}_{2}(\mathrm{~g})+\mathrm{CCl}_{4}(\mathrm{~g}) \rightarrow 2 \mathrm{CHCl}_{3}(\mathrm{~g})$

$100 \%$ selectivity for $\mathrm{CHCl}_{3}$ at moderate temperatures (not shown). At higher temperatures, however, the selectivity decreases and coke formation is observed, thus suggesting the poor long-term stability of this catalytic material.

Although surface area measurements are difficult due to the hygroscopic nature of $\mathrm{LaCl}_{3}$, it is reasonable to expect that the surface areas of the precursor and the final chlorinated material are correlated. The low conversion observed with the catalyst prepared from $\mathrm{LaCl}_{3} \cdot 7 \mathrm{H}_{2} \mathrm{O}$ can therefore be attributed to its initially low surface area of around $1 \mathrm{~m}^{2} \mathrm{~g}^{-1}$. $\mathrm{LaOCl}$, in contrast, has a relatively high initial surface area (20$30 \mathrm{~m}^{2} \mathrm{~g}^{-1}$ ), although the catalyst prepared using $\mathrm{LaOCl}$ as a precursor chlorinated with $\mathrm{HCl}$ shows only a slight improvement in activity (Figure 1). This suggests that the higher initial surface area of the $\mathrm{LaOCl}$ precursor is mostly lost during the chlorination pre-treatment. To efficiently increase the catalyst surface area, $\mathrm{LaCl}_{3}$ was therefore impregnated onto CNFs $\left(140 \mathrm{~m}^{2} \mathrm{~g}^{-1}\right)$. This support was selected because of its stability under the chlorination conditions due to the absence of lattice oxygen, which may lead to destructive adsorption of the reactants. In addition, the deposition of non-metals on carbon supports has been proven to be successful. ${ }^{[2]}$ Figure 1 demonstrates that this catalyst exhibits the highest conversion on a weight basis. Furthermore, on a volume basis (not shown), the CNF-supported catalyst is at least two orders of magnitude more active than the unsupported materials. No formation of $\mathrm{C}_{2}$ hydrocarbon products was detected during the experiments, thereby indicating that the catalyst is highly selective and that catalytic chemistry dominates over any gasphase radical reactions.

To evaluate the stability of the novel $\mathrm{LaCl}_{3} / \mathrm{CNF}$ catalyst, the reaction was run for $36 \mathrm{~h}$ at $400^{\circ} \mathrm{C}$. The results shown in Figure 2 indicate the presence of an induction period in the first hour of reaction when a significant amount of coke is

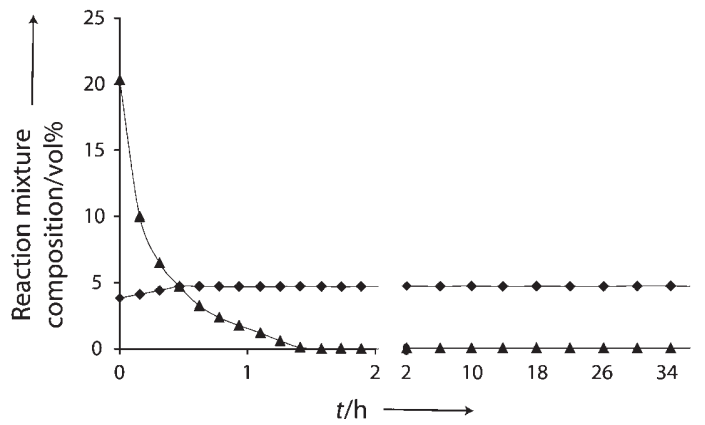

Figure 2. Reaction mixture composition $\left(\mathrm{CHCl}_{3}: \bullet ; \mathrm{C}: \mathbf{\Delta}\right)$ for the metathesis of $\mathrm{CCl}_{4}$ and $\mathrm{CH}_{2} \mathrm{Cl}_{2}$ at $400{ }^{\circ} \mathrm{C}$ over $20 \mathrm{wt} \% \mathrm{LaCl}_{3}$ supported on CNF as a function of time. The concentration of carbon was calculated based on the concentration of the gas-phase products before and after reaction ( $\mathrm{GHSV}=400 \mathrm{~h}^{-1}$; inlet concentration: $\mathrm{CCl}_{4}=\mathrm{CH}_{2} \mathrm{Cl}_{2}=4.7$ vol \% in $\left.\mathrm{He}\right)$.

formed along with $\mathrm{HCl}$ and $\mathrm{Cl}_{2}$. Nevertheless, only $\mathrm{CHCl}_{3}$ is produced as a gas-phase product. A possible explanation for the induction period is that residual $\mathrm{Ni}$ from the $\mathrm{CNF}$ growth catalyzes coke formation. $\mathrm{CNFs}$ are grown on a $\mathrm{Ni} / \mathrm{SiO}_{2}$ catalyst and then washed to remove $\mathrm{Ni}$ and $\mathrm{SiO}_{2}$. A trace amount of $\mathrm{Ni}$ becomes encapsulated in the $\mathrm{CNF}$, however, and therefore cannot be removed by washing. This Ni may become accessible during the $\mathrm{H}-\mathrm{Cl}$ exchange experiments as a result of thermal expansion and the severe chlorination conditions needed for the synthesis of $\mathrm{LaCl}_{3}$.

The likely reaction steps in the $\mathrm{H}-\mathrm{Cl}$ exchange between $\mathrm{CCl}_{4}$ and $\mathrm{CH}_{2} \mathrm{Cl}_{2}$ (Reaction 1) were evaluated by densityfunctional theory (DFT) calculations. These calculations suggest that neither $\mathrm{CCl}_{4}$ nor $\mathrm{CH}_{2} \mathrm{Cl}_{2}$ is likely to adsorb molecularly on a fully chlorinated ideal surface of $\mathrm{LaCl}_{3}$. However, it is energetically favorable for chloromethanes to split off a $\mathrm{Cl}$ atom and donate it to the surface. Although splitting off and donation of an $\mathrm{H}$ atom to the surface is calculated to be endothermic, the process can be partially compensated by exothermic chlorination of the resulting hydrocarbon fragment. It is, therefore, reasonable to assume that the reaction proceeds in two separate $\mathrm{H}-\mathrm{Cl}$ exchange steps: $\mathrm{CH}_{2} \mathrm{Cl}_{2}$ exchanges an $\mathrm{H}$ for a surface $\mathrm{Cl}$ (Reaction 2) and then $\mathrm{CCl}_{4}$ exchanges a $\mathrm{Cl}$ for a surface $\mathrm{H}$ (Reaction 3 ).

$$
\begin{aligned}
& \mathrm{CH}_{2} \mathrm{Cl}_{2}(\mathrm{~g})+\mathrm{Cl}-\mathrm{LaCl}_{2}(\mathrm{~s}) \rightarrow \mathrm{CHCl}_{3}(\mathrm{~g})+\mathrm{H}-\mathrm{LaCl}_{2}(\mathrm{~s}) \\
& \mathrm{CCl}_{4}(\mathrm{~g})+\mathrm{H}-\mathrm{LaCl}_{2}(\mathrm{~s}) \rightarrow \mathrm{CHCl}_{3}(\mathrm{~g})+\mathrm{Cl}-\mathrm{LaCl}_{2}(\mathrm{~s})
\end{aligned}
$$

The calculated energies for Reaction 2, where $\mathrm{H}$ is exchanged for a surface lattice $\mathrm{Cl}$, are high (310- 
$324 \mathrm{~kJ} \mathrm{~mol}^{-1}$ ) regardless of the presence or position of any neighboring defects ( $\mathrm{Cl}$ vacancy or $\mathrm{F}$-center $\mathrm{Cl}$ vacancy). This result suggests that gas-phase $\mathrm{CHCs}$, such as $\mathrm{CH}_{2} \mathrm{Cl}_{2}$, are unlikely to exchange their $\mathrm{H}$ for a $\mathrm{Cl}$ atom from the $\mathrm{LaCl}_{3}$ lattice. However, the calculations also suggest that the surface of $\mathrm{LaCl}_{3}$ can have both terminal lattice $\mathrm{Cl}$ and weakly held adsorbed $\mathrm{Cl}$ species (Figure $3 \mathrm{a}$ ). These species are calculated

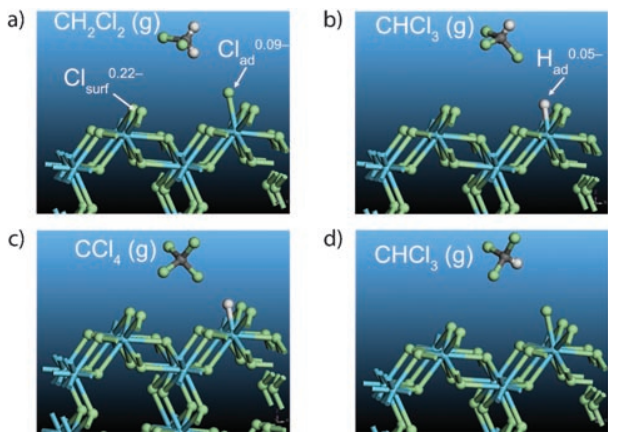

Figure 3. Proposed reaction mechanism for the metathesis of $\mathrm{CCl}_{4}$ and $\mathrm{CH}_{2} \mathrm{Cl}_{2}$ over an $\mathrm{LaCl}_{3}$ catalyst based on DFT calculations: a) gas-phase $\mathrm{CH}_{2} \mathrm{Cl}_{2}$ above the $\mathrm{LaCl}_{3}$ catalyst, b) gas-phase $\mathrm{CHCl}_{3}$ formed after $\mathrm{H}$ for-Cl exchange with the surface of the $\mathrm{LaCl}_{3}$ catalyst, c) gas-phase $\mathrm{CCl}_{4}$ above the $\mathrm{LaCl}_{3}$ catalyst, and d) gas-phase $\mathrm{CHCl}_{3}$ formed after $\mathrm{Cl}$-for- $\mathrm{H}$ exchange with the surface of the $\mathrm{LaCl}_{3}$ catalyst. Atomic charges calculated by the Hirshfeld method.

to have a significantly smaller Hirshfeld atomic partial charge of -0.09 , compared to -0.22 for surface lattice $\mathrm{Cl}$ anions, and can be viewed as a build-up of an additional $\mathrm{Cl}$ layer for the bulk structure, which means that the coordination number of surface La atoms increases from 8 to 9 , the same as for the bulk La atoms. When gas-phase $\mathrm{CH}_{2} \mathrm{Cl}_{2}$ exchanges one of its $\mathrm{H}$ atoms for an adsorbed surface $\mathrm{Cl}$ atom, the products are gas-phase $\mathrm{CHCl}_{3}$ and a surface hydride (Figure $3 \mathrm{~b}$ ). Similarly to the adsorbed surface $\mathrm{Cl}$, surface $\mathrm{H}$ is weakly bound and has only a small atomic charge of -0.05 . The calculated energy change for Reaction 2 is $210 \mathrm{~kJ} \mathrm{~mol}^{-1}$ at the adsorbed $\mathrm{Cl}$ coverage of 0.25 monolayers (ML). Gas-phase $\mathrm{CCl}_{4}$ (Figure $3 \mathrm{c}$ ) can react with the surface hydride to regenerate the adsorbed $\mathrm{Cl}$ species and form gas-phase $\mathrm{CHCl}_{3}$, as shown in Figure $3 \mathrm{~d}$. This reaction (Reaction 3 ) is predicted to be exothermic by $-225 \mathrm{~kJ} \mathrm{~mol}^{-1}$.

In summary, we have shown for the first time that $\mathrm{LaCl}_{3}$ catalyzes the hydrogen-chlorine exchange reaction of $\mathrm{CCl}_{4}$ with $\mathrm{CH}_{2} \mathrm{Cl}_{2}$ to produce $\mathrm{CHCl}_{3}$ with practically $100 \%$ selectivity and no apparent deactivation after the initial induction period. Furthermore, this is the first report whereby a catalyst based on lanthanum, which is an irreducible metal under our experimental conditions, can activate both $\mathrm{C}-\mathrm{H}$ and $\mathrm{C}-\mathrm{Cl}$ bonds in the absence of either lattice or gas-phase oxygen. Higher activity catalysts, on both a weight and volume basis, have been obtained by supporting $\mathrm{LaCl}_{3}$ on $\mathrm{CNF}$, thereby greatly increasing the surface area compared to bulk $\mathrm{LaCl}_{3}$ materials. DFT calculations suggest that the reaction can proceed through the formation and exchange of weakly adsorbed $\mathrm{H}$ and $\mathrm{Cl}$ species on the catalytic surface.

See the Supporting Information for full experimental and computational details.

Received: January 18, 2008

Published online: May 27, 2008

Keywords: density functional calculations .

heterogeneous catalysis · lanthanum - metathesis .

supported catalysts

[1] U.S. Environmental Protection Agency (EPA), Guide to Cleaner Technologies, Alternatives to Chlorinated Solvents for Cleaning and Degreasing, EPA Report 625/R-93/016, 1994.

[2] P. M. Randall, Environ. Prog. 1994, 13, 269-277.

[3] R. Bartsch, C. L. Curlin, T. F. Florkiewicz, B. Lüke, H.-R. Minz, T. Navin, R. Scannell, P. Schmittinger, E. Zelfel, Chlorine: Principles and Industrial Practice, VCH, Weinheim, 2000.

[4] United Nations Environmental Programme (UNEP), "The Montreal Protocol on Substances that Deplete the Ozone Layer" to be found under http://ozone.unep.org/pdfs/MontrealProtocol2000.pdf, 2000.

[5] U.S. Environmental Protection Agency (EPA), "Clean Air Act" to be found under http://www.epa.gov/air/caa/, 1990.

[6] V. N. Antonov, V. I. Rozhkov, A. A. Zalikin, Zh. Prikl. Khim. 1987, 60, 1347-1352.

[7] T. Ochika, T. Shimizu, T. Otsuka (Shin Etsu Chemical Company), JP 06016578, 1994.

[8] J. W. Bae, J. S. Lee, K. H. Lee, D. J. Yang, Chem. Lett. 2001, $264-$ 265.

[9] R. A. Periana, D. J. Taube, S. Gamble, H. Taube, T. Satoh, H. Fujii, Science 1998, 280, 560-564.

[10] R. A. Periana, O. Mironov, D. J. Taube, G. Bhalla, C. J. Jones, Science 2003, 301, 814-818.

[11] J. H. Lunsford, Catal. Today 2000, 63, 165-174.

[12] J. A. Labinger, J. E. Bercaw, Nature 2002, 417, 507-514.

[13] R. Mas-Ballesté, L. Que, Jr., Science 2006, 312, 1885-1886.

[14] G. J. Hutchings, C. S. Heneghan, I. D. Hudson, S. H. Taylor, Nature 1996, 384, 341 - 343 .

[15] M. S. Chen, M. C. White, Science 2007, 318, 783-787.

[16] P. Van der Avert, B. M. Weckhuysen, Angew. Chem. 2002, 114, 4924-4926; Angew. Chem. Int. Ed. 2002, 41, 4730-4732.

[17] P. Van der Avert, S. G. Podkolzin, O. V. Manoilova, H. de Winne, B. M. Weckhuysen, Chem. Eur. J. 2004, 10, 1637-1646.

[18] S. G. Podkolzin, O. V. Manoilova, B. M. Weckhuysen, J. Phys. Chem. B 2005, 109, 11634-11642.

[19] O. V. Manoilova, S. G. Podkolzin, B. Tope, J. Lercher, E. E. Stangland, J. M. Goupil, B. M. Weckhuysen, J. Phys. Chem. B 2004, 108, 15770-15781.

[20] A. W. A. M. van der Heijden, V. Bellière, L. Espinosa Alonso, M. Daturi, O. V. Manoilova, B. M. Weckhuysen, J. Phys. Chem. B 2005, 109, 23993-24001.

[21] A. W. A. M. van der Heijden, M. Garcia Ramos, B. M. Weckhuysen, Chem. Eur. J. 2007, 13, 9561-9571.

[22] S. G. Podkolzin, E. E. Stangland, M. E. Jones, E. Peringer, J. A. Lercher, J. Am. Chem. Soc. 2007, 129, 2569-2576.

[23] M. E. Jones, M. M. Olken, D. A. Hickman (The Dow Chemical Company), US 6909024, 2005.

[24] F. Winter, A. J. van Dillen, K. P. de Jong, Chem. Commun. 2005, $3977-3977$. 